\title{
GAS HOLDUP AND LONGITUDINAL DISPERSION IN DIFFERENT TYPES OF MULTIPHASE REACTORS AND THEIR POSSIBLE APPLICATION FOR MICROBIAL PROCESSES
}

\author{
J TODT, J LUCKE, $\mathrm{K}$ SCHUGERL and A RENKEN \\ Instıtut fur Technische Chemıe, Technısche Unıversıtät Hannover, D-3000 Hannover, Callınstr 46, Germany
}

(Received 31 July 1975, accepted 4 August 1976)

\begin{abstract}
Gas hold-up and liquid phase longitudinal dispersion have been measured in concurrent one-and six-stage two-phase bubble columns as well as in counter-current one-stage two- and three-phase bubble columns To describe the intensity of the longitudinal mixing the logitudinal dispersion and the backflow cell models were applied The possible influence of flud mixing on microbial processes was investugated
\end{abstract}

\section{INTRODUCTION}

Bubble columns gain increasing importance as gas-liquid reactors for continuous fermentation processes The behaviour of continuous reactor systems has often been represented by the plug flow model, the completely mixed model and the dispersion model These three different models depend on the degree of longitudinal dispersion of media Fermentations are mostly carried out in the conventional stirred-tank type vessel The flow behaviour of many continuous systems lies between the two ideal cases Examples for such models are the axial dispersion model or the $N$-tanks-in-series model These models contain parameters which describe the degree of longitudinal dispersion

For autocatalytic reactions such as those associated with many biochemical processes Bischoff [1] showed that the choice of the reactor type depends greatly on the desured conversion of substrate to cell At low conversions the stirred-tank reactor is superior to the plug flow reactor, while at high enough conversions a combination of a mixed reactor followed by a plug flow reactor would be the best choice For a given mean residence time of the liquid phase there exists a degree of longitudinal dispersion which gives rise to a maximum conversion Since the performance of a reactor system with autocatalytic kinetics depends on the axial fluid mixing, it is the objective of this work to measure the axial fiud dispersion as a function of the operating conditions for different multiphase systems (Table 1)

\section{APPARATUS}

The experimental apparatus (Fig 1) consists of a bubble column with auxiliary equipment for measurements of temperatures, pressures and flow rates, tracer injection and a recording system for the tracer concentration The column is constructed of six sections For the multistage system a perforated plate with a free area ratio of $065 \%$ was inserted between each section The bubble column could be operated with either countercurrent or concurrent contact between gas and hquid phases by reversing the liquid flow direction In the counterflow situation the tap water was fed from a storage tank to the top of the column by a centrifugal pump

The liquid was uniformly distributed across the cross

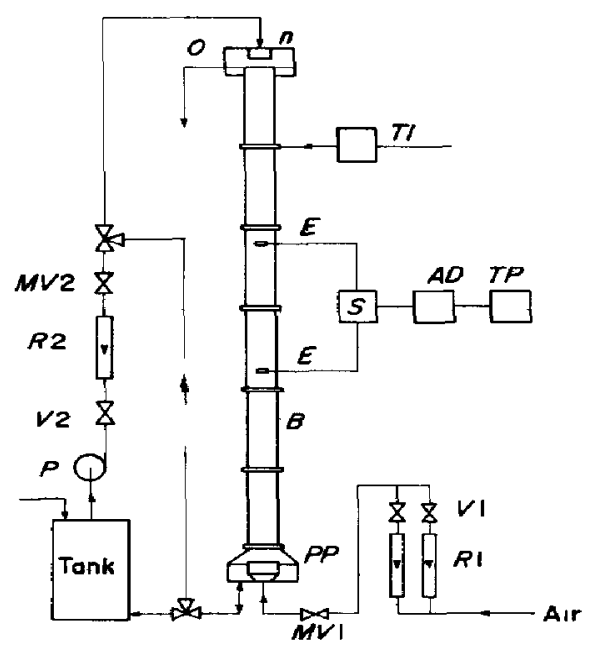

Fig 1 Experimental setup $B$, bubble column, $M V$, magnetic valve, $V$, control valve, $P$, centrifugal pump, $R$, flow meter, $O$, flow control, $P P$, gas distributor (perforated plate), $T I$, tracer injection, $E$, electrical conductuvity cell, $S$, scanner, $A D$, analog digital converter, $T P$, tape puncher, $n$, nozzle distributor

Table 1 Investigated multuphase systems

\begin{tabular}{cclccc}
\hline No & Phases & Operation & Stages & Height/cm & Diameter/cm \\
\hline 1 & 2 & concurrent & 1 & 440 & 14 \\
2 & 2 & concurrent & 6 & 440 & 14 \\
3 & 2 & countercurrent & 1 & 380 & 14 \\
4 & 3 & coumtercurrent & 1 & 380 & 14 \\
\hline
\end{tabular}


sectional area of the column by means of a nozzle distributor The air passed an oll separator, a pressure control device and entered the column from the bottom through a stainless steel perforated plate distributor The hole diameter of the plate was $05 \mathrm{~mm}$, and the free area ratio was $025 \%$ Flow rates of gas and liquid were measured with calibrated rotameters The superficial gas velocity was varied from $w_{s a}=067-1067 \mathrm{~cm} / \mathrm{sec}$, the superficial liquid velocity from $w_{S L}=070-238 \mathrm{~cm} / \mathrm{sec}$ For the three-phase countercurrent system hollow glass beads (Microballons FT 102, Emerson \& Cumming Inc, Mass, U S A ) 125-250 $\mu \mathrm{m}$ in diameter were used as solid particles They had a mean density of $028 \mathrm{~g} / \mathrm{cm}^{3}$ when measured with water

Liquid axial mixing was measured by pulse tracer technique using a $20 \% \mathrm{NaCl}$-solution The tracer was injected into the column through a small stanless steel tube The opening time of the magnetic valve varied between 03 and 10 secs Concentration of tracer in the reactor was measured at two locations in the column by means of conductivity cells which were installed at a distance of $L=100 \mathrm{~cm}$ from each other This tracer technique has the advantage that a mathematical perfect pulse is unnecessary The tracer concentration was recorded by data logger on paper tape punch as a discrete function of tume The gas hold-up $\epsilon_{G}$ was determined by measuring the pressure drop at several points in the column, and from residence time distributions as well as by measuring the height of the aerated liquid $H$, and that of the liquid without aeration $H_{0}$

$$
\epsilon_{G}=\frac{w_{s o}}{w_{G}}=\frac{H-H_{0}}{H}
$$

(For more experimental detauls see 13 )

\section{RESULTS}

\section{Gas hold-up and relative velocity}

In Fig 2 the relative gas fraction is shown as a function of the superficial gas velocity for the investigated systems For all systems gas holdup increases rapidly in the lower range of gas velocities and tends to level off at higher velocities The average gas hold-up in the three-phase system arr-tap water-glass beads is higher than in solids-free systems at the same linear liqund velocity, and it increases with the amount of solid particles in the reactor The superficial liquid velocity $w_{S L}$ has only a slight influence on $\epsilon_{G}$ (Fig 3 ) In countercurrent systems the gas fraction increases with increasing $w_{S L}$, but decreases in concurrent systems

To compare these results with the ones calculated by some published equations, on Fig 4 the ranges of the $\epsilon_{G}$-values of the present paper measured in concurrent and counter-current one stage two-phase systems for different liquid flow rates as function of the gas fiow rate are plotted together with the $\epsilon_{G}$-values calculated for the present system by equations of Burkel[14] (curve $a$ ), Hugmark [15] (curve b), Mersmann[16] (curve $c$ ), Akıta [17] (curve $d$ ) and Gestrich [18] (curve $e$ )

One can recognize from $F_{1 g} 4$ that the $\epsilon_{o}$-values measured on the concurrent one stage-two-phase systems

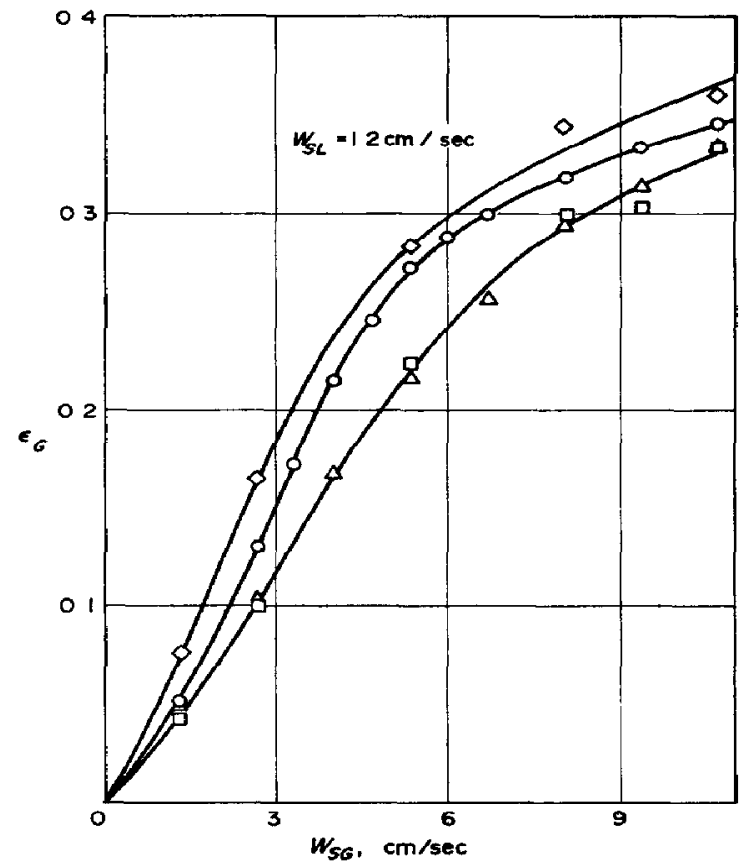

Fig 2 Gas hold-up as function of the superfical gas velocty $w_{\text {sL }}=12 \mathrm{~cm} / \mathrm{s}$ Two-phase system-counter-current one stage, $\mathrm{O}$, concurrent one stage, $\square$, multistage, $\Delta$ Three-phase systemcounter-current one stage, $\diamond$

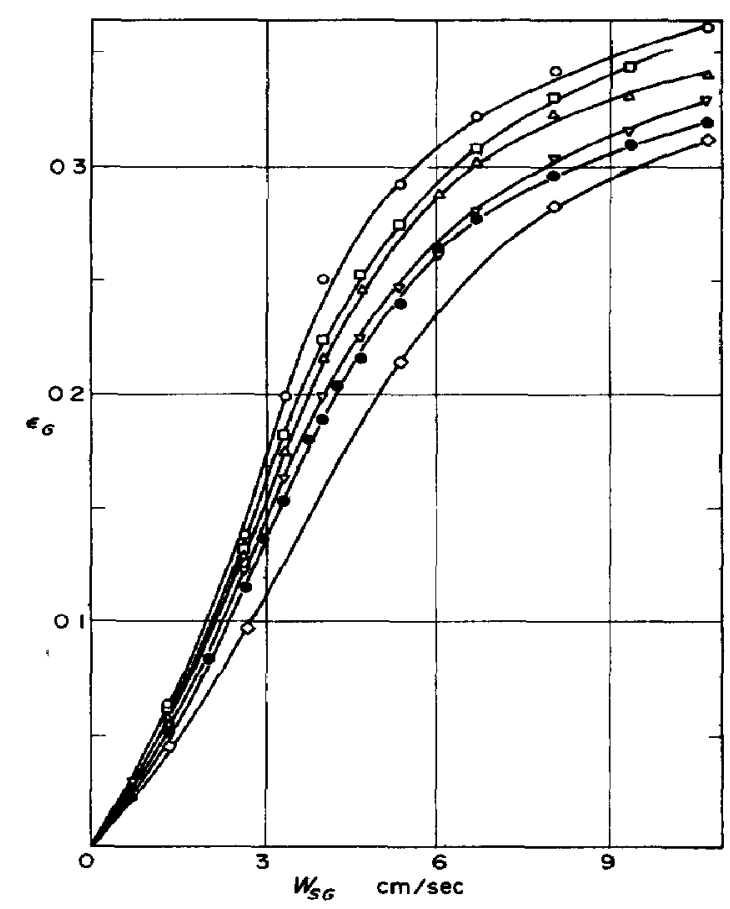

Fig 3 Gas hold-up as function of the superficial gas and hqud velocity One-stage two-phase system concurrent $w_{s L}=220, \diamond$ Countercurrent $w_{s z}=238 \mathrm{~cm} / \mathrm{s} O, 168, \square, 120, \triangle, 070, \nabla, 0$,

agree with the ones calculated by equation of Gestrich [18] and/or Mersmann[16] only for low and/or high gasfiow rates The $\epsilon_{G}$-values in counter-current systems are between the curves $e$ and $c$ of Gestrich and Mersmann for low gas flow rates and agree partly with the curve $c$ 


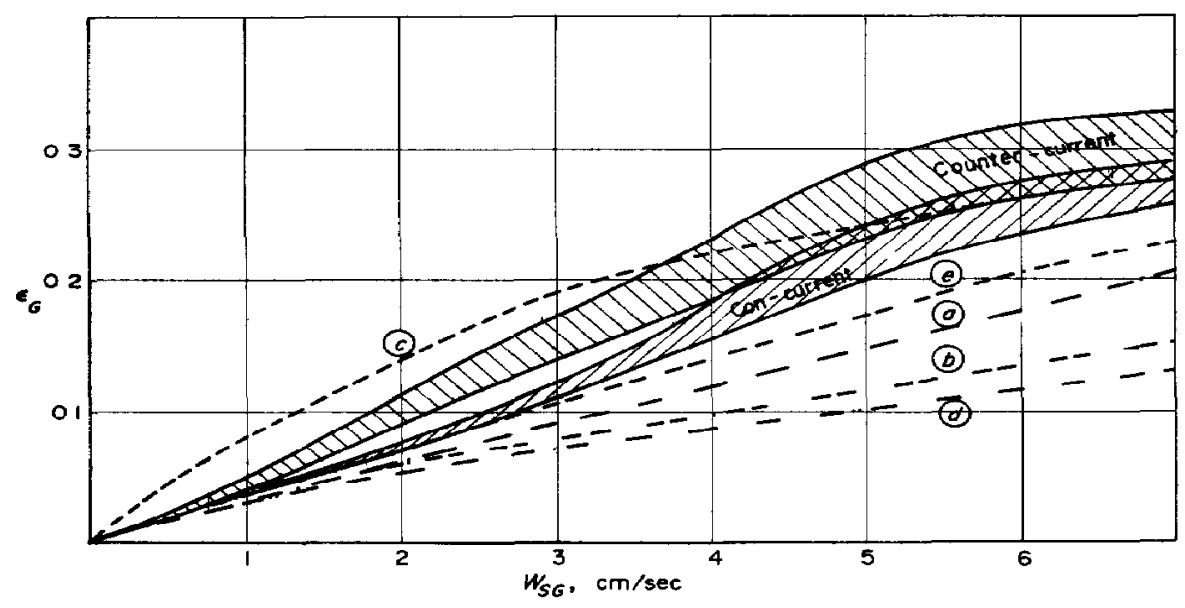

Fig 4 Comparison of the ranges of the $\epsilon_{G}$-values of the present paper measured in concurrent and countercurrent one-stage two-phase systems for different hquid flow rates as function of the gas flow rate $w_{s G}$ with calculated $\epsilon_{0} G$-values according to (a) Burkel[14], (b) Hughmark [15], (c) Mersmann [16], (d) Akita [17], (e) Gestrich [18]

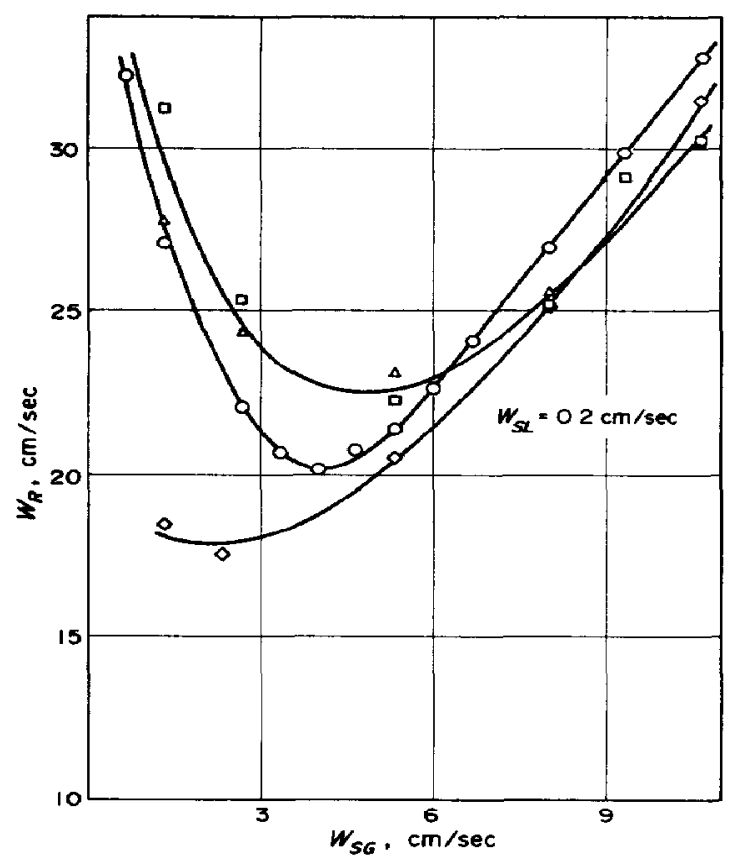

F1g. 5 Relative velocity between gas and hquid as function of the superficial gas velocity $w_{S L}=12 \mathrm{~cm} / \mathrm{s}$ Two-phase systemcountercurrent one stage, $O$, concurrent one stage, $\square$, mults-

tage, $\Delta$ Three-phase system-countercurrent one stage. $\Delta$

for high gas flow rates No one of these recommended equations describes the behaviour of $\epsilon_{G}$ in the whole investigated range of gas flow rates, probably because these equations do not consider the influence of different type of gas distributors on the gas holdup $\epsilon_{G}$

The relative velocity $w_{R}$ between gas and lquid phase is calculated from hold-up data, the superficial gas and hquid velcoities ( + countercurrent, - concurrent)

$$
w_{R}=w_{G} \pm w_{L}=\frac{w_{S O}}{\epsilon_{G}} \pm \frac{w_{S L}}{1-\epsilon_{G}}
$$

In Fig 5 the relative velocrty measured in the four systems is plotted against the superficial gas velocity For the two-phase systems the slope of the curves is negative at small values of $w_{s G}$, and the relative velocity passes through a minimum at a superficial gas velocity of $4-5 \mathrm{~cm} / \mathrm{sec}$ For superficial gas velocities below $5 \mathrm{~cm} / \mathrm{sec}$ the bubbles emerging from the perforated plate are characterised by a unform bubble size distribution and a small average diameter At higher gas velocitıes the flow is turbulent with random circulation patterns Coalescence increases bubble size which in turn gives a larger effective gas velocity $w_{G}$ For the three-phase system $w_{G}$ decreases at small gas rates because of the hindering effect of the solid particles

\section{Longitudinal fluid dispersion}

Two models were applied to characterise axıal mixing effects within the flow reactor the axtal dispersion model and the backflow cell model The dispersion model is described by the following dimensionless equation, derived from an unsteady-state material balance on the tracer component [2]

$$
\frac{\partial C^{*}}{\partial \theta}+\frac{\partial C^{*}}{\partial x^{*}}=\frac{1}{P e} \frac{\partial^{2} C^{*}}{\partial x^{* 2}}
$$

This model is based on the assumption that the two transport mechanisms. bulk flow and longitudinal dispersion, are independent of radial position The dimensionless Peclet-number $P e=w_{L} L / D_{L}$ indicates the degree of mixing within within the reactor

The backflow cell model[3] consists of $N$ perfectly mixed cells of equal volume with constant net flow rate $V_{F}$ and with constant backflow rate $V_{B}$ from each cell back to the preceding cell The backflow ratio $\beta=V_{B} / V_{F}$ and the number of cells $N$ used in this model characterise axial dispersion A material balance for the inert tracer solute in cell $\imath$ yields an ordinary differential equation

$$
\frac{1}{N} \frac{\mathrm{d} C_{t}^{*}}{\mathrm{~d} \theta}=(1+B) C_{i-1}^{*}-(1+2 \beta) C_{i}^{*}+\beta C_{i+1}^{*}
$$


A set of dimensionless equations is obtained by writing material balances about each cell The parameters $P e$ or $\mathrm{N}, \boldsymbol{\beta}$ must be determıned by experiment A pulse of tracer is injected into the flowing stream, and concentration measurements were taken at two points within the test section, which are far enough from the entrance and exit sections

A widely-used technique for estımating the parameters involves the calculation of the variances of the experimental concentration curves at the two points The difference between them can be related to the parameters

Another way of representing the relation between the two concentration curves is by use of the transfer function concept The model transfer function, which is defined as the ratio between the Laplace-transform of the output divided by the Laplace-transform of the input, can be found by taking the Laplace-transform of each sides of eqns (3) and (4) The system transfer function for the axial dispersion model is [4] (neglecting the end effects)

$$
F\left(s^{*}, P e\right)=\exp \left[\frac{P e}{2}\left(1-\sqrt{ }\left(1+\frac{4 s^{*}}{P e}\right)\right)\right]
$$

and for the backfiow cell model

$$
F\left(s^{*}, N, \beta\right)=\xi N
$$

where

$$
\begin{aligned}
\xi=\frac{1}{2 \beta}\left[\left(1+2 \beta+s^{*}\right.\right. & (N) \\
& \left.-\sqrt{ }\left[\left(1+2 \beta+s^{*} / N\right)^{2}-4 \beta(1+\beta)\right]\right]
\end{aligned}
$$

The experimental transfer function can be evaluated from experimental residence time distribution data obtained by numerical integration of the transient response to an imperfect pulse

$$
F_{M}\left(s^{*}\right)=\bar{C}_{2}^{*}\left(s^{*}\right) / \bar{C}_{1}^{*}\left(s^{*}\right)
$$

The model parameters were estımated by a least-squared error analysis of the transformed response data

$$
\phi\left(P_{\mathrm{J}}, s^{*}\right)=\sum_{i=1}^{n}\left[F_{M}\left(s_{i}^{*}\right)-F\left(s_{i}^{*}, P_{j}\right)\right]^{2}
$$

The analysis requires that the function $\phi\left(P_{j}, s_{i}^{*}\right)$ is minumized with respect to the model parameters $P_{j}(J=$ $1,2, \quad m)$ for selected values of the dimensionless Laplace-variable $s^{*}=s \bar{t}$ For the determination of the least-squares estimates the methods of Gauss-Seidel[5] and Marquardt [6] were applied The first method converges rapudly, if the first approxumate for the unknown parameters are quite good Otherwise, the method diverges The modified steepest-descent method of Marquardt converges slower than the first method, but has the distinct advantage of converging for almost any first approximate This method seeks to calculate corrections in such a way that at each iteration the value of $\phi\left(P_{i}\right.$, $\left.s^{*}\right)$ will decrease most rapidly Integer values of $s^{*}$ ranging from 1 to 5 were used in fitting the data The least-squares method gives directly a numerical estımate of the quality of the fit for different data sets or models
The standard error of estımate is calculated as

$$
S E=\sqrt{\left(\frac{\phi\left(P_{j}, s_{i}^{*}\right)}{n-m}\right)}
$$

where $n$ is the number of data points used for the fit and $m$ the number of parameters The model and the experimental transfer functions are in good agreement The standard deviation of the fitted Peclet-number $(\mathrm{Pe}=1720)$ is $S E=2519 \times 10^{-3}$, and of the fitted parameters of the backflow cell model $(N=24, \beta=1344) \quad S E=$ $2544 \times 10^{-3}$

A relation between the parameters of both models can be obtained by equating the variances of the axial dispersion model and of the backflow cell model[3]

$$
P e=\frac{2 N}{1+2 \beta}
$$

Figures 6-8 show the effect of the gas rate on the Peclet-number $P e$ and the backflow ratio $\beta$

For all investigated systems axial dispersion increases with increasing superficial hquid and superficial gas velocities Very high gas rates cause coalescence, and the degree of mixing is considerably increased The intensity of mixing is lower in a multistage bubble column than in the other systems at the same gas rate

Empirical correlations for fluid mixing within the different systems have been derived from the data of this work

$$
P_{e}^{*} \quad w_{L} / \frac{\mathrm{cm}}{\sec }=B_{0}\left[\frac{w_{S G}}{w_{S L}}\right]^{B_{1}}
$$

The axıal dispersion can be characterised by a modified

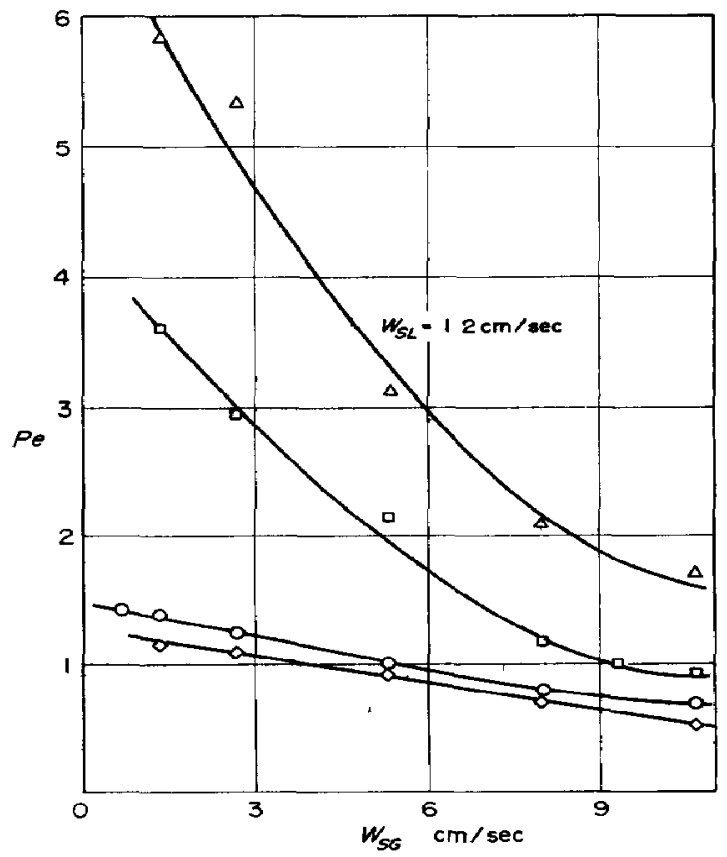

Fig 6 Effect of the superficial gas velocity on the Pe-number Two-phase system $w_{g x}=12 \mathrm{~cm} / \mathrm{s}$ For symbols see Fug 5 


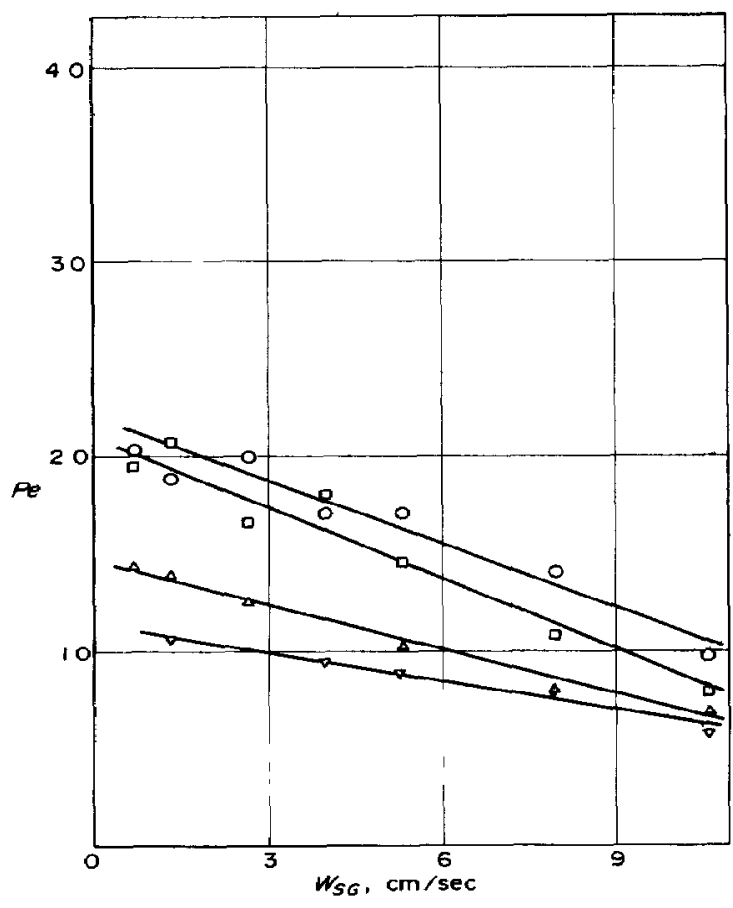

Fig 7 Effect of the superficial gas velocity on the Pe-number for different superficial liquad velocitues Two-phase countercurrent, one stage $w_{s t}=238 \mathrm{~cm} / \mathrm{s}, O, 168, \square, 120 \mathrm{~cm} / \mathrm{s}, \Delta, 071 \mathrm{~cm} / \mathrm{s}, \nabla$

Peclet-number $P e^{*}=w_{R} d / D_{L}$ based on the column diameter $d$ and the relative velocity $w_{R}$ This nonlinear equation can be transformed to linear form by taking logarithms of both sides of eqn (11) The parameters $B_{0}$ and $B_{1}$ of the linear model were estimated by the method of least-squares (Table 2) Fig 9 shows the experimental data and the estimated regression lines The confidence intervals were determined for a significance level of $\alpha=005$ [5]

Figure 10 shows the data $P e^{*} w_{L}$ compared with values calculated from eqn (11) Most of the data fall within the dashed lines which represent a mean relative error of
Table 2 Parameters of eqn (11)

\begin{tabular}{ccc}
\hline No & $B_{0}$ & $B_{1}$ \\
\hline 1 & $14577 \pm 0423$ & $-0589 \pm 0081$ \\
2 & $24944 \pm 0602$ & $-0552 \pm 0105$ \\
3 & $6014 \pm 0154$ & $-0307 \pm 0034$ \\
4 & $2551 \pm 0061$ & $-00044 \pm 00003$ \\
\hline
\end{tabular}

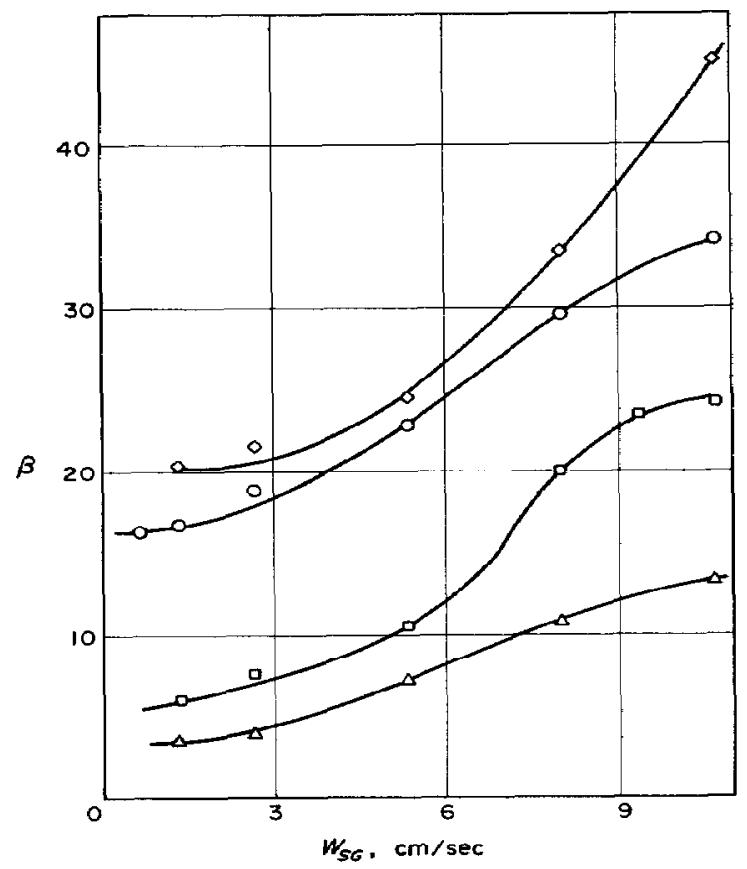

Fig 8 Backfiow-ratio $\beta$ as function of the superficial gas velocity (for symbols see Fig 5)

$\pm 20 \%$ The results have been compared with the literature data on axial liquid mixing By using the $w_{S O} / w_{S L}$-values of the published data[7-10] $P e^{*} w_{L}$ was calculated by eqn (11) and $B_{0}$ and $B_{1}$ values of Table 2

By use of the axial dispersion model (3) in conjunction with the Monod growth kinetics[11] the influence of fiud

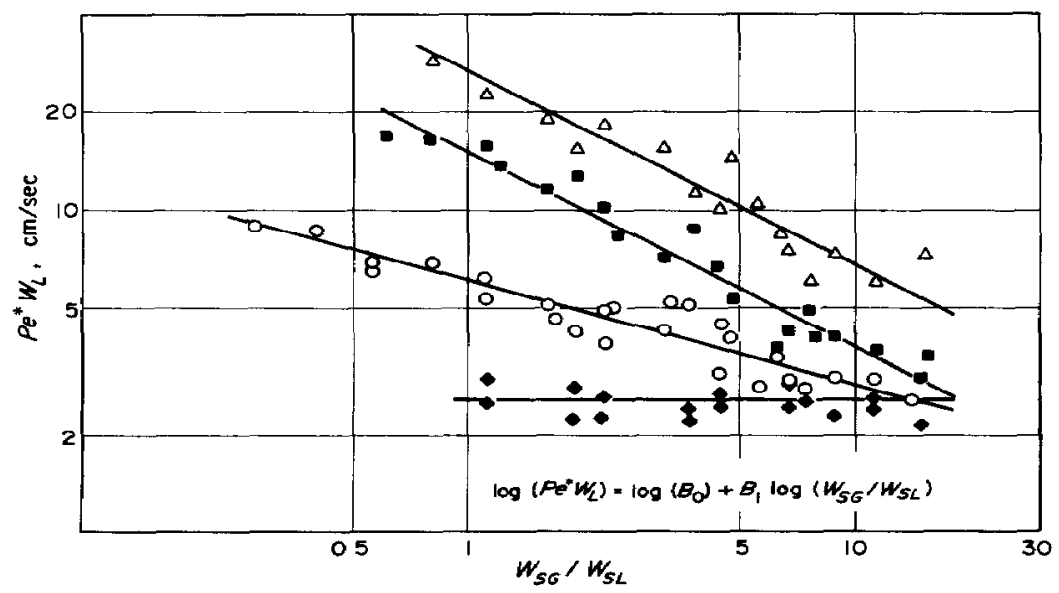

Fig 9 Correlation for the modified $P e$-number Two-phase system-countercurrent one stage, $O$, concurrent one stage, $\square$, multistage, $\triangle$ Three-phase system-countercurrent one stage, 
mixing on the performance of a microbial process was investigated. The performance equations derived from the steady state material balance for substrates and cells were solved by a numencal technique based on the principle of collocation methods [12]

For solving the equations the so-called Danckwerts' boundary conditions were used Figure 11 shows the effect of the Peclet-number on the exit concentration of substrate $C_{E S}^{*}$ for different Damkohler-numbers $\mathrm{Da}=$ $k \vec{t}$ The results were obtained by considering following values dimensionless saturation constant $K *=K / C_{I S}=$ 05 , dimensionless initial cell concentration $C_{\text {IC }}^{*}=0$ At

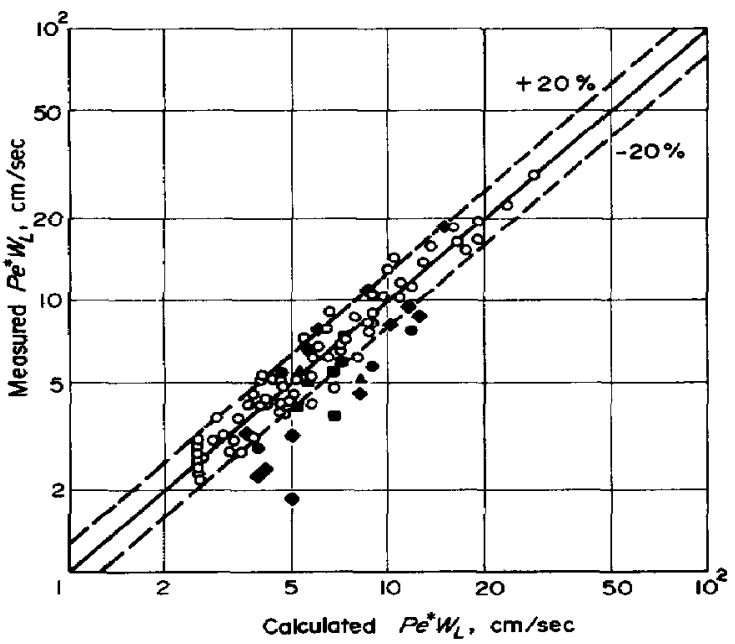

Fig 10 Comparison of experımental and calculated modified $P e$-numbers Langemann[8], $\bullet$, Reth[7], A, Argo[9], D, Towell[10],, present work, $O$

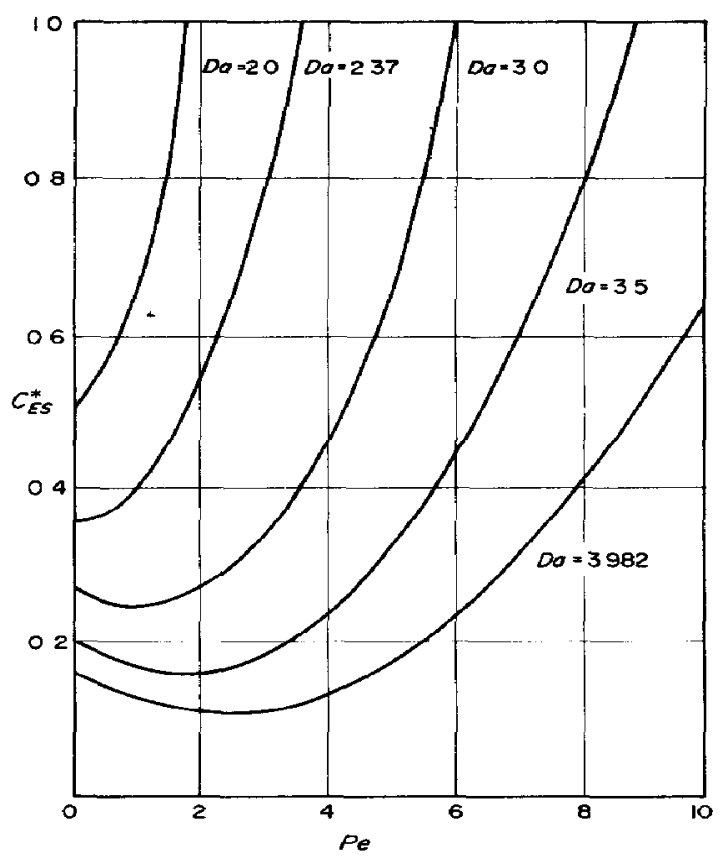

Fig 11 Effect of the Pe-number on the exut concentration of substrate for vanous $D a$-numbers low conversions, which correspond lower values of $D a$, the sturred tank vessel is the most efficient reactor The critical value of $D a$, for which a stirred tank reactor is still superior to the dispersion model reactor, 1s 237 For any value of $D a$ greater than this critical value the dispersion model reactor is the choice to attain the maximum conversion The optimal Peclet-number is about 1 for $D a=3$ with a maximum conversion of $76 \%$ If the Peclet-number is greater than 6 for $D a=3$ the growth of cells cannot be maintained The cells tend to be washed out because of insufficient residence time These results show that there exists an optimal Peclet-number (longitudinal fiud dispersion) in a bubble column with autocatalytic kınetics for a given set of $D a, C_{I C}^{*}$ and $K^{*}$.

As the desired conversion increases a point is reached where a combined system of a sturred tank vessel followed by a plug flow reactor turns out to be an optimum[11] Such a system can be approached by a mult1-stage column Recently bubble column fermentors with recycle are recommended because of their favourable fiud-dynamical properties (low energy requirement with regard to their specific surface area) For such systems $\left(C_{I_{C}}^{*}>0\right)$ the optimum Peclet number increases as $C$ f $_{C}$ increases if all other parameters remain constant For large values of $C_{1}^{*}$ the Peclet number should be as large as possible Since the optimum Peclet number can vary between 0 and $\infty$ as function of $K^{*}, D a$ and $C_{r C}^{*}$, mult1-stage bubble columns with adjusted $P e$ numbers are in generally superior to one-stage columns

Acknowledgement-The authors gratefully acknowledge the financial support of Bundesmınıster für Forschung und Technologie, Bonn

\section{NOTATION}

$B_{0}, B_{1}$ coefficients of eqn (11)

$C$ tracer concentration, $\mathrm{g} / \mathrm{cm}^{3}$

$\bar{C}(s)$ Laplace-transform of $C(t)$

d column diameter, $\mathrm{cm}$

$D$ axial dispersion coefficient, $\mathrm{cm}^{2} / \mathrm{sec}$

$D a$ Damkohler-number $(D a=k \quad \bar{t})$

$F$ transfer function

$k$ maximum specific growth rate when the substrate concentration is not limiting the rate of growth $h^{-1}$

$K$ concentration of substrate at which the specific growth rate observed is one half the maximum value

$L$ distance between the two measuring points, cm

$n$ number of data points

$N$ number of cells

$P_{\text {I }}$ set of parameters

$P e$ Peclet-number $\left(P e=w_{L} L / D_{L}\right)$

$P e^{*}$ modified Peclet-number $\left(P e=w_{R} d / D_{L}\right)$

$s$ Laplace-variable, $\sec ^{-1}$

$t$ time, sec

$\bar{t}$ mean residence time, sec

$V$ volumetric flow rate, $\mathrm{m}^{3} / \mathrm{h}$

w linear velocity, $\mathrm{cm} / \mathrm{sec}$

$\boldsymbol{x}$ axial distance, $\mathrm{cm}$ 
Greek symbols

$\beta$ backflow ratio $\left(\beta=V_{B} / V_{F}\right)$

$\epsilon_{G}$ gas hold-up

$\theta$ dimensionless tıme

Sub-, Superscripts

1,2 first, second measuring point

$B$ backward

$C$ cell

$E$ exit

$F$ forward

$G$ gas

I Initial

$L$ liquid

$S$ superficial, substrate

* dimensionless variable

\section{REFERENCES}

[1] Bischoff K B, Can J Chem Engng 196644281

[2] Ostergaard $\mathbf{K}$ and Michelsen $M$ L, Can $J$ Chem Engng 196947107

[3] Roemer M H and Durbin L D I \& EC Fundl 1967 6(1) 120
[4] Michelsen M L and Ostergaard K, Chem Engng Scl 1970 25583

[5] Himmelblau D M, Process Analysts by Statustical Methods J Wiley, New York 1970

[6] Marquardt D W, Chem Engng Prog 1959 55(6) 65

[7] Rerth T Renken S and Israel B A, Chem Engng Sct 1958 25619

[8] Langemann $H$ and Taubert C, Verfahrenstechn 19682417

[9] Argo W B and Cova D R I\& EC Proc Des Develop 19654 352

[10] Towell G D and Ackermann G H, Fifth European, Sec Intern Symp on Chem React Engng (1972)

[11] Chen G K C, Fan L T and Enckson L E, Can J Chem Engng 197250157

[12] Fan L T, Chen G $K$ C and Enckson L E, Chem Engng Scl 197126379

[13] Todt J , Dissertation, TU Hannover 1974

[14] Burkel W, Chem Ing Techn 197446205

[15] Hughmark G A, Ind Engng Chem Process Des Dev 19676 218

[16] Mersmann VDI-Forschungsheft 491 VDI-Verlag Düsseldorf 1962

[17] Akıta $\mathrm{K}$ and Yoshida F, Ind Engng Chem Proc Des Dev 19731276

[18] Gestrich W and Rähse W, Chem Ing Techn 1975478 